\title{
Diversity analysis of chickpea (Cicer arietinum L.) germplasm and its implications for conservation and crop breeding
}

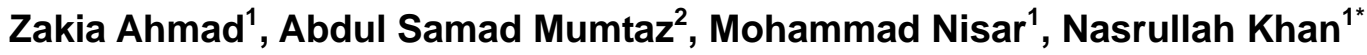 \\ ${ }^{1}$ Department of Botany, University of Malakand, Chakdara, Pakistan; *Corresponding Author: nasrullahdushkheli@yahoo.com \\ ${ }^{2}$ Department of Plant Sciences Quaid-i-Azam University, Islamabad, Pakistan
}

Received 1 June 2012; revised 8 July 2012; accepted 24 July 2012

\section{ABSTRACT}

The exploration of genetically variable accessions is the key source of germplasm conservation and potential breeding material for the future. The more diverse group of cultivars provides an ample opportunity to breeders for releasing new and superior varieties, considering their quality traits for direct commercial utilization. In this study, we assessed the genetic diversity of Cicer arietinum 70 accessions from Pakistan and USA using morphological traits, seed protein and molecular markers. Based on four morphological traits, the average coefficient of variation was calculated as $56.8 \%$ with significant correlation among yield traits. The analysis revealed that the accessions 1898,2819 , 3022, 3037, 3040, 3043, 3054, 3059 and 3063 were best in performance with a total of $12 \%$ environmental error. The cluster analysis based on protein data revealed $50 \%$ genetic diversity among accessions. The clustering pattern did not show any grouping that could be attributed to either the geographic distribution or the field performance. For molecular characterization of germplasm 5 PCR based RAPD primers, OPA4, OPA9, OPG13, UBC181 and UBC733b used were found to be polymorphic with $37 \%$ genetic diversity among local and exotic accessions. Whereas, 3 SSR primers viz., CaSTMS2, CaSTMS15 and CaSTMS21 scored the genetic variability up to $55 \%$ by cluster analysis through UPGMA percent disagreement. The primers, TA72 and TA130 were linked with yield related traits, indicated highest dissimilarity index value $(0.69)$ and notable variation in the identified promising lines. The Morphometric, Biochemical and Molecular markers reported here, are helpfulto assess the extent of genetic diversity among Chickpea accessions and can be used to identify the unreported cultivars with desirable quantitative traits for improving Chickpea yield in Pakistan. Based on the study, the accessions 3043 and 3054 have been recommended to the breeders for their future use in multiplication and screening against various diseases.

Keywords: Chickpea; Morphological Characterization; SDS-PAGE; RAPD; SSR; Cluster Analysis

\section{INTRODUCTION}

Among legumes, chickpea (Cicer arietinum L.) ranks third worldwide [1], and its seeds contain $>20 \%$ protein that is an important energy source for human [2]. Chickpea is currently grown at about 10.7 million hectares worldwide with an average annual production of 8.2 million tons [3]. The developing countries share more than $95 \%$ of the area, production and consumption of chickpea. It is grown mainly in South East Asian countries with significant cultural, religious and nutritional value. Two main types of cultivated chickpea are Kabuli (white seeded) and desi (brown seeded), representing two diverse gene pools [4]. In Pakistan, the chickpea growing area has increased from 0.88 million hectares in 19811983 to 1.07 million hectares in 2005-2007 with net production of 0.73 million tones at an annual rate of 1.9 percent [3]. Though chickpea is cultivated on large area, but its production remained low probably due to lime induced Iron deficiency along with other biotic and abiotic stresses $[5,6]$.

The production rate over the past decades remained short of the actual demand that may be attributed to the lack of improved technologies, unavailability of healthy seeds to farmers and environmental stresses besides competition with major crops like wheat and cotton [7]. Furthermore, the agricultural practices and successive 
breeding has narrowed down the genetic base of cultivated chickpea [8]. This has promoted the search for new sources of variation that might be useful for chickpea breeding program [9]. The estimation of genetic diversity based on morphological characterization and biochemical analysis using SDS-PAGE [10] and molecular evaluation using RAPD markers [11] and SSR markers [12] have been reported and being carried out for detection of diversity in chickpea cultivars. All the techniques for estimation of genetic diversity have their own implication and validity, none is superior, but have specific implications for crop improvement or germplasm management. In the present study, we reported morphological, biochemical and molecular markers to characterize and compare local and exotic chickpea germplasm to assess the genetically variable and promising lines and their inference to yield related traits, viz., 100 seed weight and seed size for yield improvement of cultivated chickpea in Pakistan.

\section{MATERIALS AND METHODS}

Seventy chickpea accessions were obtained from the gene bank of Plant Genetic Resource Program (PGRP), National Agriculture Research Centre, Islamabad, Pakistan (Catalogue). These accessions were planted under field conditions at research area of University of Malakand, Chakdara, Khyber Pakhtunkhwa $\left(34^{\circ} 40^{\prime} \mathrm{N}\right.$, lat $72^{\circ} 03^{\prime} \mathrm{E}$ long, alt $728 \mathrm{~m}$ asl) that is a unique area for its bio-geographic feature. All accessions were planted in du- plicated randomized complete block design keeping row length of $5 \mathrm{~m}$ with $75 \mathrm{~cm}$ row distance, respectively.
The recommended culturing practices were followed throughout the cropping season to achieve healthy and vigorous crop. The accessions were investigated under field conditions during three consecutive years, i.e., 2008-2009, 2009-2010 and 2010-2011 (sowing during November and harvesting in April for all the cropping season). For data scoring five competitive plants were sampled for 100-seed weight, grain yield, total biomass, whereas harvest index was expressed in percentage as a ratio between grain yield and total biomass.

To investigate the genetic diversity on the basis of protein, sodium dodecyl sulfate polyacrylamide gel electrophoresis (SDS-PAGE) was carried with $12 \%$ polyacrylamide gel, in a discontinuous buffer system according to the method described by [13].

For molecular analyses, the genomic DNA from a single dry seed was isolated by modified method of [14], total eight RAPD and seven SSR markers were utilized, out of these five RAPD and five SSR markers indicated polymorphism shown in (Tables $\mathbf{1}$ and 2). The PCR for RAPD was conducted for 40 cycles with the initial denaturation temperature at $94^{\circ} \mathrm{C}$ for $2 \mathrm{~min}$, annealing at $36^{\circ} \mathrm{C}$ for one minute and final extension temperature for each primer was fixed at $72^{\circ} \mathrm{C}$ for $10 \mathrm{~min}$. For SSR Primers the thermal cycler was optimized with initial denaturation at $94^{\circ} \mathrm{C}$ for $3 \mathrm{~min}$, annealing at $55^{\circ} \mathrm{C}$ for 1 min and final extension at $72^{\circ} \mathrm{C}$ for $7 \mathrm{~min}$.

The data scored for morphological traits were subjected to statistical analysis including correlation coefficient and frequency distribution, whereas the presence (1) and absence (0) of each band in case of biochemical and

Table 1. RAPD Primers used for genetic diversity in chickpea germplasm.

\begin{tabular}{ccccc}
\hline Primer Name & sequence & No. of bands & Polymorphic loci & Fragment size \\
\hline UBC 181 & ATGACGACGG & 17 & $63 \%$ & $300-6000$ \\
UBC 733b & GGGAAGGGAG & 17 & $56 \%$ & $250-2500$ \\
OPA4 & AATCGGGCTG & 9 & $87 \%$ & $300-1750$ \\
OPA9 & GGGTAACGCC & 6 & $93 \%$ & $350-2500$ \\
OPG13 & CAGCACCCAC & 16 & $97 \%$ & $250-1350$ \\
\hline
\end{tabular}

Table 2. SSR primers used for chickpea germplasm analysis.

\begin{tabular}{ccc}
\hline Primer & Sequence forward/ Reverse & Molecular size \\
\hline CaSTMS2 & ATTTTACTTTACTACTTTTTTCCTTTCAATAAATGGAGTGTAAATTTCATGTA & $114 \mathrm{bp}$ \\
CaSTMS15 & CTTGTGAATTCATATTTACTTATAGATATCCGTAATTTAAGGTAGGTTAAAATA & $159 \mathrm{bp}$ \\
CaSTMS21 & CTACAGTCTTTTGTTCTTCTAGCTT ATATTTTTTAAGAGGCTTTTGGTAG & $60 \mathrm{bp}$ \\
TA72 & GAAAGATTTAAAAGATTTTCCACGTTATTAGAAGCATATTGTTGGGATAAGAGT & $198 \mathrm{bp}$ \\
TA130 & TCTTTCTTTGCTTCCAATGT GTAAATCCCACGAGAAATCAA & $219 \mathrm{bp}$ \\
\hline
\end{tabular}


molecular markers were subjected to statistical analysis for the estimation of genetic disagreement with the help of STATISTICA 7.0 for Windows using UPGMA.

\section{RESULTS}

The morphological data analysis based on four quantitative traits showed variation among chickpea accessions (Table 3). The correlation coefficient among quantitative traits revealed significant association of 100 seed weight with grain yield and biomass for both the years. The grain yield had positive significant correlation with total biomass and harvest index, whereas biomass and 100 seed weight were negatively correlated to harvest index (Table 4).

When compared the frequency distribution data for accessions, a notable variation was recorded for seed weight and harvest index where $47.14 \%$ of which were placed in the frequency class $\leq 22.5-32.4$ of "seed weight" and $\leq 12.5$ - 23.4 for "harvest index" in 2010 . The overall variation observed could be attributed to $5 \%$ environmental error (EE) for "seed weight" reporting, that this to be a rather stable trait, while $19 \%$ EE was observed in "harvest index". The data recorded in 2008 and 2009 scored more than $50 \%$ accessions as one frequency class while, this threshold could not be achieved for
2010-2011. Hence this pattern of distribution varied much with a higher level (19\%) variation attributed to environmental error. However, a different pattern was revealed for grain yield where relatively half, i.e., 51\% accessions were placed in one frequency class $(1.1-58.3)$ and the remaining of the accessions populated other frequency classes. However, more than $50 \%$ were observed in the same class range in 2011 , associated with $12 \%$ environmental error. The observations regarding total biomass in 2011 a comparatively high percentage of accessions as $48 \%$ and $36 \%$ were placed in a frequency classes (50 - 279) and (280 - 509) followed by 44\% were also placed in the same range in 2009 with $8 \%$ environmental error (Figure 1).

Data analysis further evaluated that the accessions 3022, 3040, 3059, and 3063 performed better for a single trait or "total biomasses". The "grain yield" performance was found best in the genotypes 2819, 3039 and 3056 for "100 seed weight" and "harvest index" it was found in accession 1898. For two traits, 100 seed weight and total biomass the promising accession was however, 3037. Similarly, 3043 and 3054 were found best for three quantitative traits "100 seed weight", "grain yield" and "total biomass" (Table 5).

A total of 16 high molecular weight polypeptide bands

Table 3. Basic statistics of the 4 quantitative traits of 70 chickpea germplasm.

\begin{tabular}{|c|c|c|c|c|c|c|}
\hline Traits & Mean & S.E & Std.dev. & Minimum & Maximum & C.V\% \\
\hline 100/Seed Weight & $\begin{array}{l}27.41 \mathrm{a} \\
26.94 \mathrm{~b} \\
27.70 \mathrm{c}\end{array}$ & $\begin{array}{l}1.32 \mathrm{a} \\
1.37 \mathrm{~b} \\
1.38 \mathrm{c}\end{array}$ & $\begin{array}{c}11.02 \mathrm{a} \\
11.6 \mathrm{~b} \\
11.6 \mathrm{c}\end{array}$ & $\begin{array}{l}12.36 \mathrm{a} \\
8.53 \mathrm{~b} \\
8.50 \mathrm{c}\end{array}$ & $\begin{array}{l}57.76 \mathrm{a} \\
64.51 \mathrm{~b} \\
56.80 \mathrm{c}\end{array}$ & $\begin{array}{l}40.21 \mathrm{a} \\
42.53 \mathrm{~b} \\
41.73 \mathrm{c}\end{array}$ \\
\hline Grain Yield & $\begin{array}{l}90.20 \mathrm{a} \\
83.82 \mathrm{~b} \\
72.78 \mathrm{c}\end{array}$ & $\begin{array}{l}6.81 \mathrm{a} \\
6.56 \mathrm{~b} \\
7.92 \mathrm{c}\end{array}$ & $\begin{array}{l}56.97 \mathrm{a} \\
54.89 \mathrm{~b} \\
66.23 \mathrm{c}\end{array}$ & $\begin{array}{c}1.20 \mathrm{a} \\
7.10 \mathrm{~b} \\
10.50 \mathrm{c}\end{array}$ & $\begin{array}{l}287.6 \mathrm{a} \\
316.7 \mathrm{~b} \\
228.9 \mathrm{c}\end{array}$ & $\begin{array}{l}63.15 \mathrm{a} \\
65.49 \mathrm{~b} \\
91.00 \mathrm{c}\end{array}$ \\
\hline Total Biomass & $\begin{array}{l}442.7 \mathrm{a} \\
447.8 \mathrm{~b} \\
424.8 \mathrm{c}\end{array}$ & $\begin{array}{l}28.30 \mathrm{a} \\
32.16 \mathrm{~b} \\
32.30 \mathrm{c}\end{array}$ & $\begin{array}{c}236.8 \mathrm{a} \\
269.05 \mathrm{~b} \\
270.2 \mathrm{c}\end{array}$ & $\begin{array}{c}50.00 \mathrm{a} \\
101.00 \mathrm{~b} \\
87.00 \mathrm{c}\end{array}$ & $\begin{array}{l}1150.00 \mathrm{a} \\
1322.00 \mathrm{~b} \\
1422.00 \mathrm{c}\end{array}$ & $\begin{array}{l}53.48 \mathrm{a} \\
60.08 \mathrm{~b} \\
63.61 \mathrm{c}\end{array}$ \\
\hline Harvest Index & $\begin{array}{l}21.60 \mathrm{a} \\
20.75 \mathrm{~b} \\
18.72 \mathrm{c}\end{array}$ & $\begin{array}{l}1.34 \mathrm{a} \\
1.28 \mathrm{~b} \\
1.62 \mathrm{c}\end{array}$ & $\begin{array}{l}11.23 \mathrm{a} \\
10.72 \mathrm{~b} \\
13.58 \mathrm{c}\end{array}$ & $\begin{array}{l}0.22 \mathrm{a} \\
4.91 \mathrm{~b} \\
1.73 \mathrm{c}\end{array}$ & $\begin{array}{l}53.38 \mathrm{a} \\
48.83 \mathrm{~b} \\
53.02 \mathrm{c}\end{array}$ & $\begin{array}{l}52.01 \mathrm{a} \\
51.65 \mathrm{~b} \\
72.56 \mathrm{c}\end{array}$ \\
\hline
\end{tabular}

C.V\%: Represent coefficient variation percentage; $\sigma 2$ Ava = 56.8\%; a: Represent year 2008-2009; b: Represent year 2009-2010; c: Represent year 2010-2011.

Table 4. Correlation coefficient of 70 genotypes among quantitative traits harvested during 2008-2009, 2009-2010 and 2010-2011.

\begin{tabular}{|c|c|c|c|}
\hline & $100 /$ seed weight & Grain yield & Total biomass \\
\hline Grain yield & $\begin{array}{c}0.36^{*} \mathrm{a} \\
\mathbf{0 . 5 7 ^ { * * }} \mathbf{b} \\
0.21^{*} \mathrm{c}\end{array}$ & & \\
\hline Total biomass & $\begin{array}{c}0.56^{* *} \mathrm{a} \\
\mathbf{0 . 6 5 ^ { * * }} \mathbf{b} \\
0.39^{*} \mathrm{c}\end{array}$ & $\begin{array}{l}0.67^{* *} \text { a } \\
\mathbf{0 . 3 3 ^ { * }} \mathbf{b} \\
0.45^{*} \mathrm{c}\end{array}$ & \\
\hline Harvest index & $\begin{array}{c}-0.03 \text { a } \\
\mathbf{0 . 0 1} \mathbf{b} \\
-0.07 \text { c }\end{array}$ & $\begin{array}{l}0.46^{* *} \text { a } \\
\mathbf{0 . 3 3} 3^{*} \mathbf{b} \\
0.68^{* *} \text { c }\end{array}$ & $\begin{array}{l}-0.21 \mathrm{a} \\
-\mathbf{0 . 3 2} \mathbf{b} \\
-0.19 \mathrm{c}\end{array}$ \\
\hline
\end{tabular}

\footnotetext{
*Highly significant; ${ }^{* *}$ Significant. a: 2008-2009, b: 2009-2010, c: 2010-2011; $\mathrm{P} \leq 0.01$, highly significantly correlated; $\mathrm{P} \leq 0.05$, significantly correlated.
} 


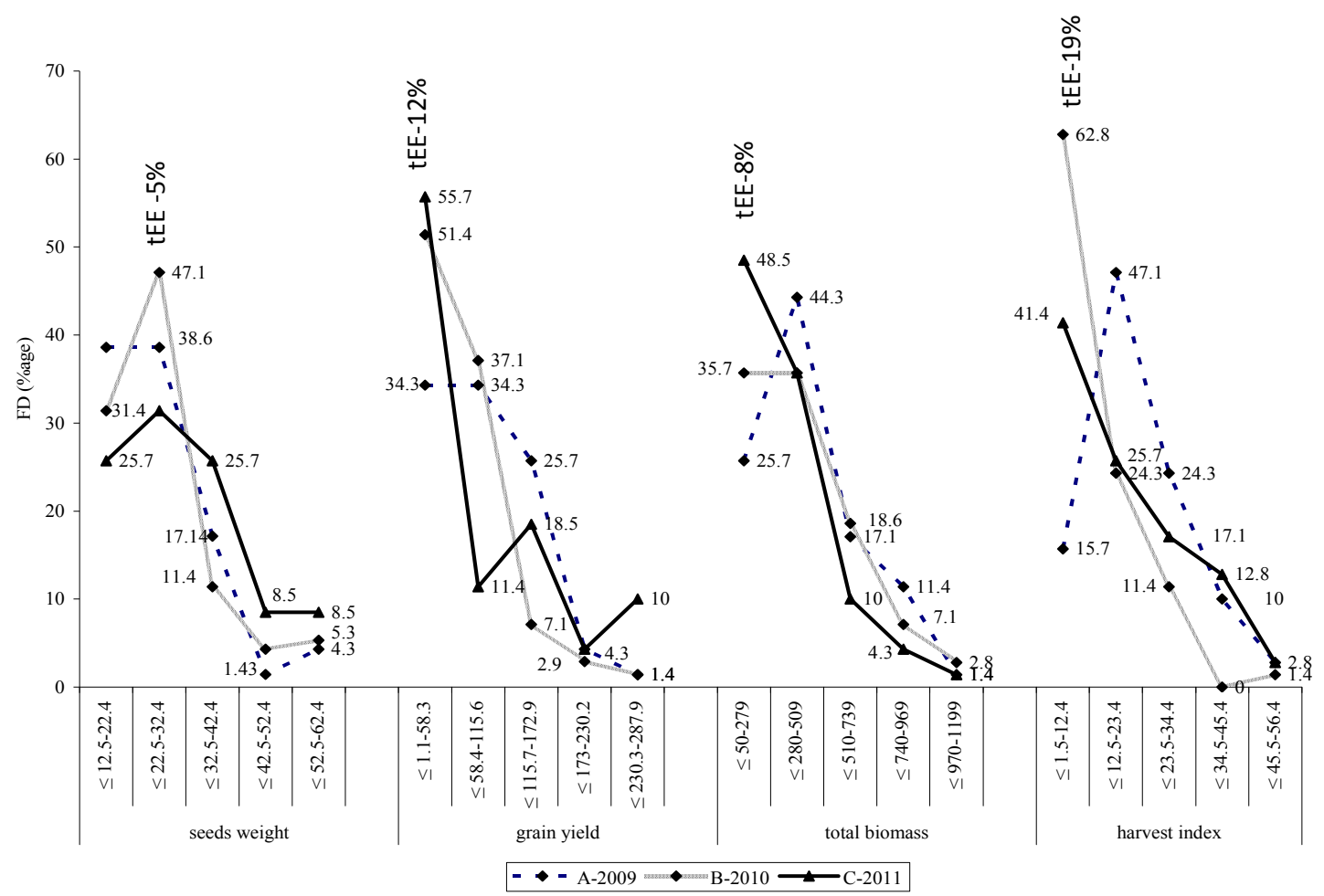

Figure 1. Comparative Picture showing frequency distribution of three years data collected during 2008 to 2011 of chickpea germplasm. tEE-total environmental error across the years.

Table 5. Selection of genotypes on the basis of best performance for the year 2008-2009, 2009-2010 and 2010-2011.

\begin{tabular}{|c|c|c|c|c|c|c|c|}
\hline Traits & G-1 & G-2 & G-3 & G-4 & G-5 & G-6 & G-7 \\
\hline 100 Seed weight & $3037^{* *}$ & $3043^{* * *}$ & $3054^{* * *}$ & $3056^{*}$ & & & \\
\hline Grain yield & $2819^{*}$ & $3039^{*}$ & $3043^{* * *}$ & $3054^{* * *}$ & & & \\
\hline Total Biom & $3022^{*}$ & $3037^{* *}$ & $3040^{*}$ & $3043^{* * *}$ & $3054^{* * *}$ & $3059^{*}$ & $3063^{*}$ \\
\hline Harvest Index & $1898^{*}$ & - & - & - & - & - & - \\
\hline
\end{tabular}

G: Genotype; ${ }^{*}$ Best performance for a single trait; ${ }^{* *}$ Best performance for two traits; ${ }^{* * *}$ Best performance for three traits.

were scored, the position of each band was tagged through an arrow (Figure 2). The low molecular weight bands were not reproducible, therefore these were not considered in the study. Cluster analysis of 70 accessions reported $50 \%$ genetic diversity with most of the accessions clustering in three clusters as C-1 comprised of 5 (USA) and 4 (Pakistani), C-2 the largest group with 33 USA, 13 (Pakistani) and C-3 with 6 USA and 7 Pakistani accessions. Contrary to this, 3027 and 3045 (USA) were remained unresolved. Hence these accessions were grouped as $13.2 \%, 67.6 \%$ and $19.1 \%$ of the total population respectively (Table 6, Figure 3).

At 0.25 linkage distance the dendrogram based on RAPD markers was divided into seventeen clusters for 70 chickpea accessions, showed $37 \%$ genetic diversity. The analysis sorted the total accessions into two main groups, which were further divided into 17 clusters.
Cluster-12a grouped together the promising lines 3059 and 3043 at a same linkage distance 0.14 , while 3039 , 3063 at 0.20 and 3056 at 0.13 linkage distance are closely allied with each other. In a same way, 3022 and 3040 occupied cluster-10 and 11 respectively at similar linkage distance 0.19 . The genotype 3054 of cluster- 5 and 3037 here showed slight difference in their banding pattern found as 23\% - 25\% dissimilar (Figures 4(a), (b) and 5).

A total of 8 SSR markers, were screened for estimation of genetic diversity in Chickpea lines, in which only 5 were found to be polymorphic (Figures 6(a) and (b)). The dendrogram formed by UPGMA percent indicated $55 \%$ genetic diversity among the accessions and divided them into 4 clusters at a linkage distance 0.5 (Figure 7). The dissimilarity matrix values of 70 chickpea genotypes SSR Primers were ranged from 0.36 to 0.69 . The primers 


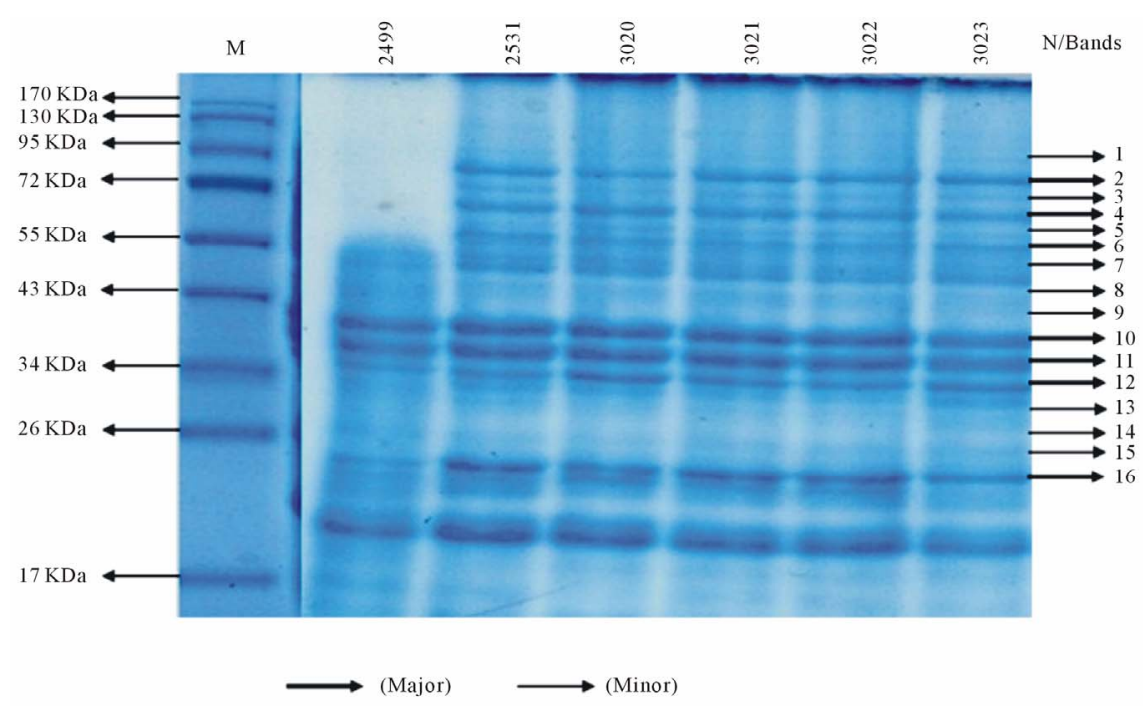

Figure 2. Electrophorogram showing the distribution of different molecular weight protein in Chickpea germplasm arrows indicate the presence of band, KDa-K-Daltons.

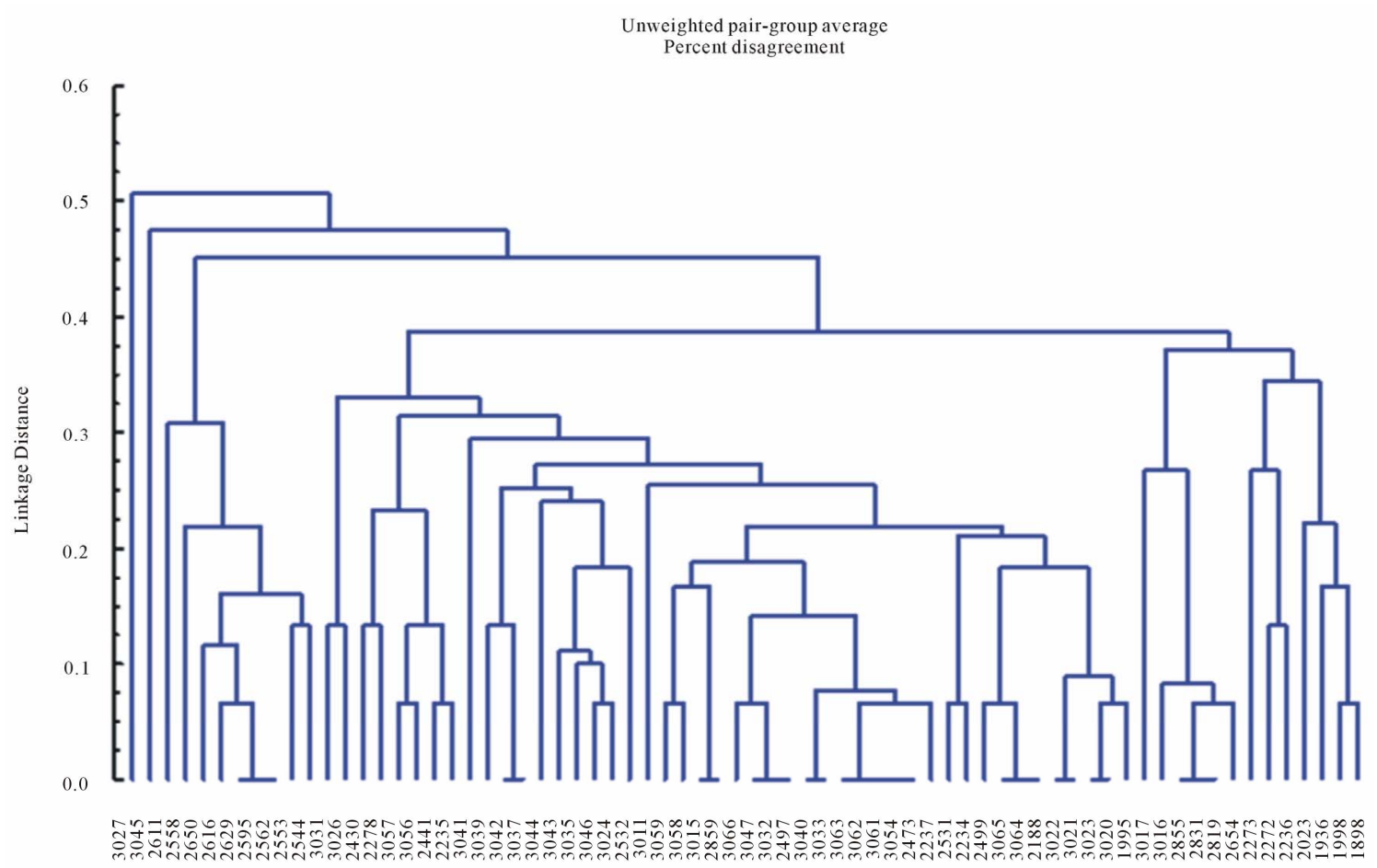

Figure 3. Cluster analysis of chickpea 70 genotypes using SDS-PAGE.

Table 6. Cluster analysis based on disagreement by using SDS-PAGE in 70 chickpea genotypes.

\begin{tabular}{ll}
\hline Clusters & \multicolumn{1}{c}{ Genotype } \\
\hline C-1 & $2611,2650,2616,2629,2595$ (USA) \\
& $2558,2562,2553,2544$ (Pakistan) \\
& $3031,3026,3041,3057,3056,3039,3042,3037,3044,3043,3035,3046,30243011,3059,3058,3015,3066,3047$, \\
& $3032,3040,3033$ 3063, 3062, 3061, 3054, 2859, 3065, 3064, 3022, 3021 3023, 3024 (USA) \\
& $2430,2278,2441,2235,2532,2497,2473,2237,2531,2234,2499,2188,1995$ (Pakistan) \\
& $3017,3016,2855,2831,2819,2654$ (USA) \\
& $2273,2272,2236,2023,1936,1998,1898$ (Pakistan) \\
\hline
\end{tabular}



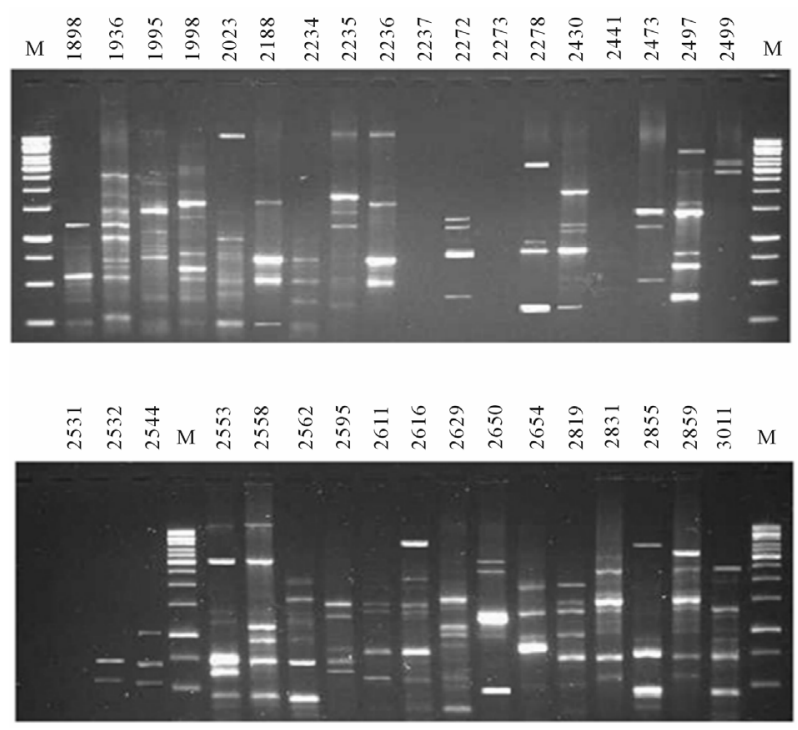

(a)
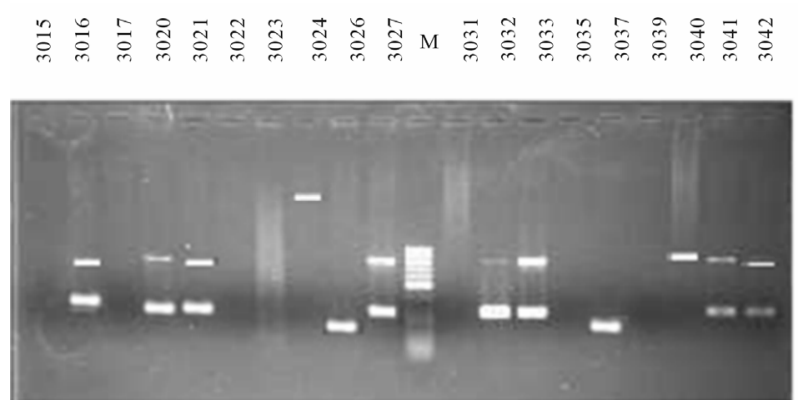

(b)

Figure 4. (a) RAPD-PCR amplification products of chickpea accessions using Primer UBC181; (b) RAPD-PCR amplification products of Chickpea genotypes using Primer OPA9.

CaTMS2 and CaTMS21 showed low dissimilarity index (0.36) while TA130 and TA72 however scored the highest dissimilarity index value (0.69) Table 7.

\section{DISCUSSION}

Internationally Cicer is an important and mandate crop both at the International Crops Research Institute for the Semi-Arid Tropics (ICRISAT), located in India and at the International Center for Agricultural Research in the Dry
Areas (ICARDA), in Syria. However, a number of challenges exist for Cicer as a crop. There are several pests and diseases of chickpea (such as Aschochyta blight). The further development of accession level data and subsequent comparison of this data across collections would greatly facilitate the identification of unique accessions. Further work is needed on characterizing and evaluating the collections and on making the information openly available. A common platform for information on Cicer germplasm is of high priority. Through the generation of accession-level data and by improving the accessibility of information on accessions globally, unique genetic resources may be identified and prioritized for support. Only through such efforts, as well as the formation of stronger collaborative relationships with user communities, is there likely to be a significant increase in the use of collections by plant breeders and others.

Genetic diversity provides a sort of insurance against complete destruction of plant populations in the event of natural disaster. In extreme cases, low genetic diversity may lead to complete elimination of some plant species resulting in loss of overall biological diversity [15]. In this investigation, $56.8 \%$ average coefficient of variation was observed. This level of variation in the study indicates the strength and potential of the collected germplasm. The plant breeder easily establishes different potential combinations for chickpea cultivar identification. Significant correlation in yield contributing traits was observed which is helpful for the establishment of traits improvement. In correlation studies 100 seed weight was found positively highly significantly correlated with grain yield in 2008-2009 and 2009-2011, while, positively significantly correlated with total biomass in 2010 . In a similar way grain yield has positive significant correlation with harvest index in 2008-2009, 2011 and this relation was highly significant with the same trait during 2010. The total biomass however, observed negatively correlated with harvest index during the years 2009, 2010 and 2011.

The level of environmental error (EE) greatly affects the composition of genotypes in breeding strategies. The low level of EE usually having less effect on plant genotype composition than that of its high level [16]. Well-

Table 7. Dissimilarity matrix values of SSR analysis for chickpea genotypes.

\begin{tabular}{|c|c|c|c|c|c|}
\hline & CATMS2-GD & CATMS15-GD & CATMS21-GD & TA72-100S.wt & TA130-seed size \\
\hline CATMS2-GD & 0.00 & & & & \\
\hline CATMS15-GD & 0.40 & 0.00 & & & \\
\hline CATMS21-GD & 0.36 & 0.47 & 0.00 & & \\
\hline TA72-100S.wt & 0.43 & 0.51 & 0.44 & 0.00 & \\
\hline TA130-seed size & 0.51 & 0.51 & 0.61 & 0.69 & 0.00 \\
\hline
\end{tabular}




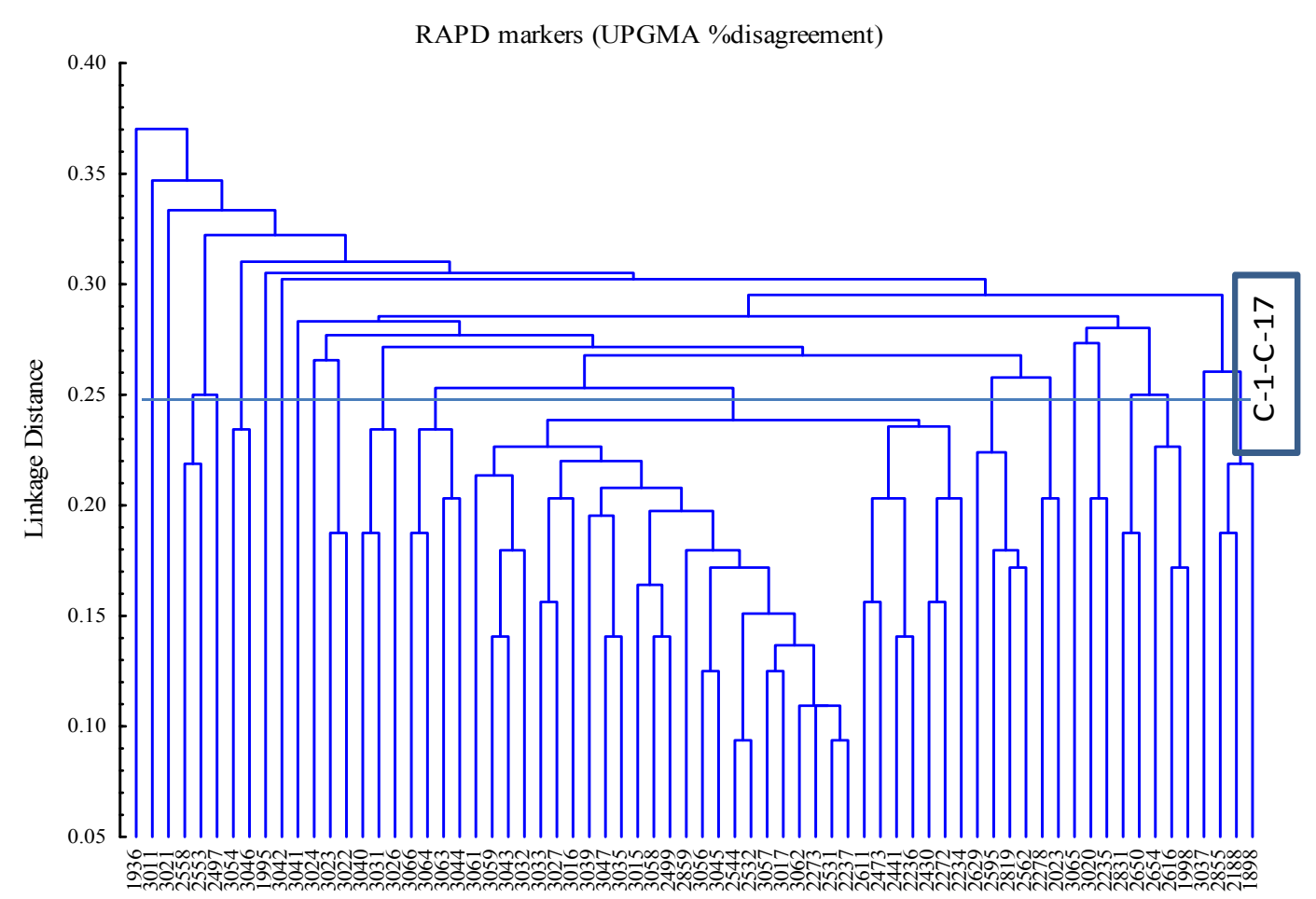

Figure 5. Dendrogram of 70 chickpea accessions based on RAPD data using UPGMA.

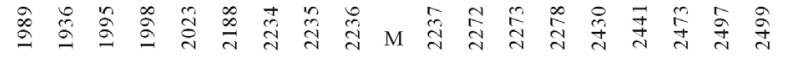

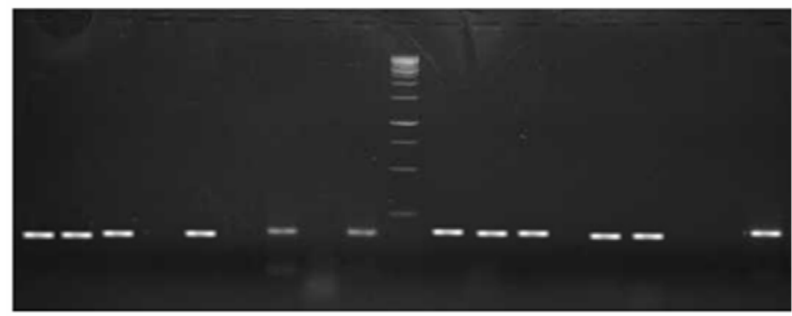

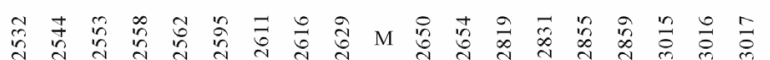

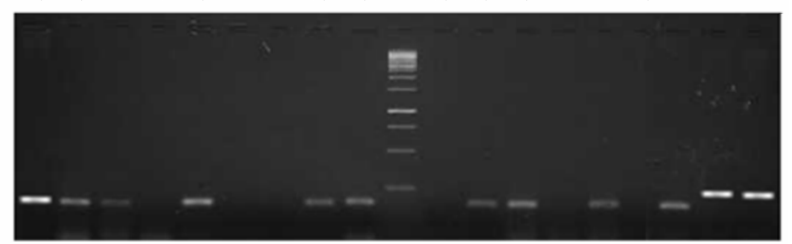

(a)
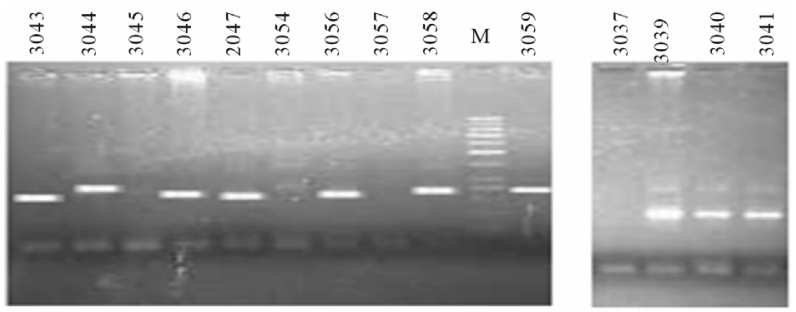

(b)

Figure 6. (a) SSR-PCR amplification products of chickpea local and exotic accessions using SSR primers; (b) SSR-PCR amplification products of chickpea genotypes using primer CaSTMS2. defined cultivars adapted to local environments are developed for specific areas. These cultivars are genetically diverse in nature and contribute significantly to the variation in chemical composition and Biological efficacy of the plant products [17].

This study identified 11 best performance and stable accessions; one can easily select breeding lines for chickpea breeding program. Among 11 accessions; lines 3043 and 3054 could be used directly as cultivars. These two selected lines will be grown in field trials for multiplication and Screening against different diseases, and ultimately will be available to the farmers. Crop stability, is the ability of a crop to exhibit minimum interaction with both predictable and unpredictable environments. The Study of genotype and environment interaction $(\mathrm{G} \times$ E) is important to plant breeders because it can limit the progress in the selection process, hence is a basic cause of differences between genotypes for yield stability. Varieties that show low $\mathrm{G} \times \mathrm{E}$ interaction and have high stable yields are desirable for crop breeders and farmers, because it indicates that the environments have less effect on the performance of accessions and their yields are largely due to their genetic composition [18]. The SDSPAGE analysis resussslted in $50 \%$ genetic diversity among 70 genotypes was not based on their geographic distribution and moreover, these lines were not separated on their performance.

The evaluation and characterization of the accessions through PCR based markers i.e., RAPD, which were 


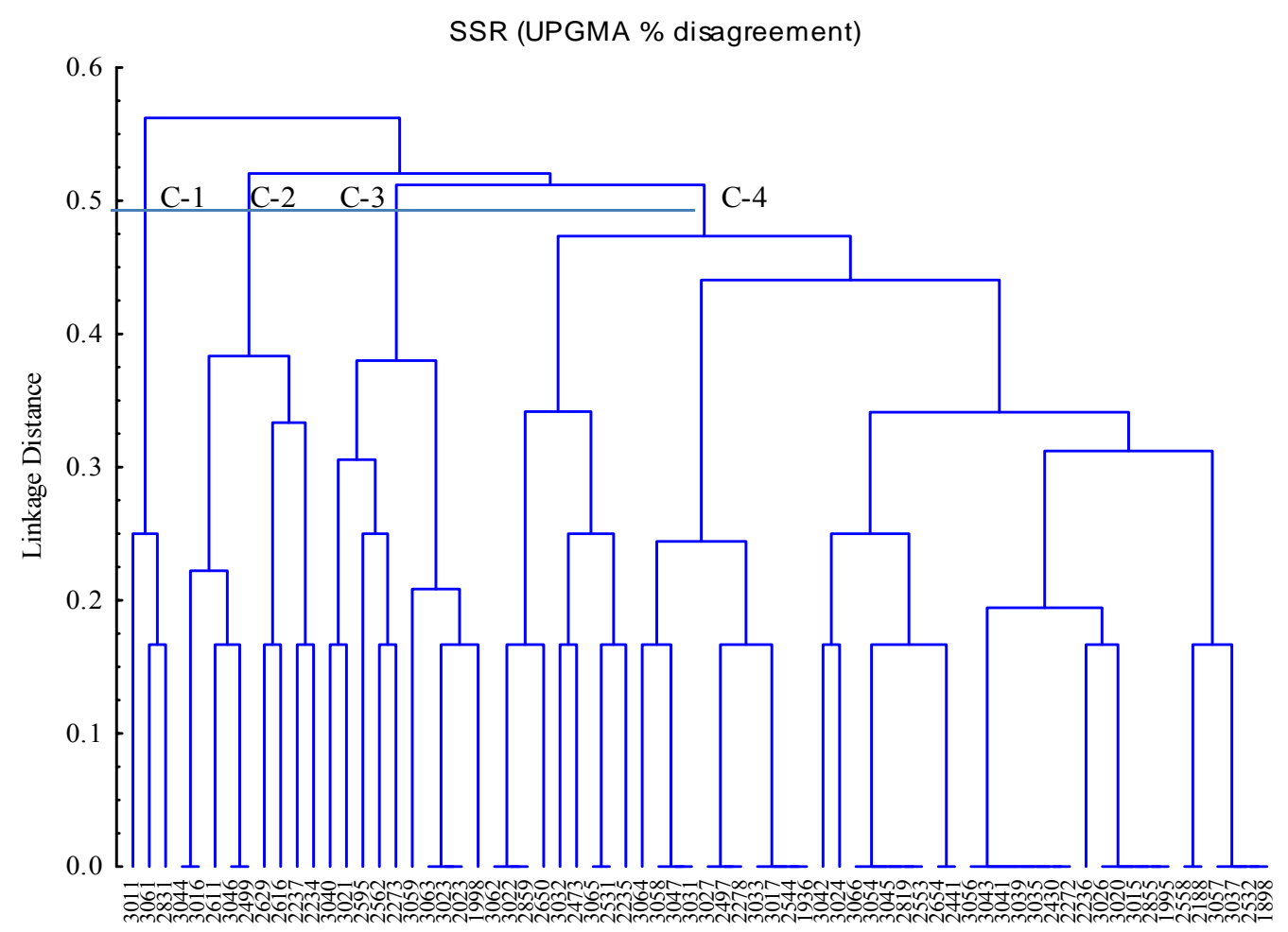

Figure 7. Dendrogram of 70 chickpea accessions based on SSR data using UPGMA percent disagreement.

found to be polymorphic showed $37 \%$ genetic diversity among the sorted lines. Traits determined by RAPD technique are highly polymorphic and useful in studies on chickpea concerning its genetic diversity, phylogeny and evolutionary biology [19].

The analysis performed by using SSR markers for determination of genetic diversity in local and exotic lines viz., CaSTMS2, CaSTMS15 and CaSTMS21 could differentiate the accessions on the basis of unique or rare alleles, also have been reported [20,21]. Moreover, the identification and evaluation of trait linked genes through molecular markers TA72 and TA130 can also provide a strongest tool to breeders for chickpea yield improvement in Pakistan.

Importantly, seed weight was also proposed as an accurate measure of chickpea seed size [22]. Therefore, to produce seed of a specific size, and to meet a specific market demand through targeted breeding, knowledge of the genetics that determine seed size is required. A large seed size variation exists within and between chickpea types, with some desi types as large as Kabuli types and some Kabuli types as small as desi types. Most of the previous investigations have relied on F2 and backcross populations for seed size segregation analysis and used 100-seed weight data for QTL analysis in chickpea. That may be targeted for future marker-assisted breeding strategies [23].

It is therefore, suggested that molecular markers i.e.,
RAPD, SSR, SNP and AFLP could be useful for the characterization and grouping of germplasm on the basis of their origin and performance [24,25].

\section{REFERENCES}

[1] Food and Agricultural Organization (2006). http://www.fao.org/waicent/statistic.asp

[2] Singh, R., Sharma, P., Rajeev, K., Varshney, R. and Sharma, S.K. and Singh N.K. (2008) Chickpea improvement: Role of wild species and Genetic Markers. Biotechnology \& Genetic Engineering Reviews, 25, 267-314. doi:10.5661/bger-25-267

[3] Food and Agricultural Organization (2005-2008) Food and agricultural organization statistical database. Rome. www.faostat.fao.org

[4] Nawroz, A.R.T. and Hero, F.H.K. (2011) Determination of genetic relationship among some varieties of Chickpea (Cicer arietinum L.) in Sulaimani by RAPD and ISSR Markers. Jordan Journal of Biomedical Science, 4, 7786.

[5] Upadhyaya, H.D., Bramel, P.J. and Singh, S. (2001) Development of a chickpea core subset using geographic distribution and quantitative traits. Crop Science, 41, 206221. doi:10.2135/cropsci2001.411206x

[6] Cani, H. and Toker, C. (2009) Evaluation of annual wild Cicer species for drought and heat resistance under field conditions. Genetic Resources and Crop Evolution, 56, 16. doi:10.1007/s10722-008-9335-9

[7] (2010) Chickpea germplasm collection database. 
http://www.icrisat.org/crop

[8] Robertson, L.D., Ocampo, B. and Singh, K.B. (1997) Morphological variation in wild annual Cicer species in comparison to the cultigen. Euphytica, 95, 309-319. doi:10.1023/A:1003004516921

[9] Brown, B.A.H.D., Burdon, J.J. and Grace, J.P. (1990) Genetic structure of Glysine canescens. A perennial relative of soybean. TAG Theoretical and Applied Genetics, 79, 729-736. doi:10.1007/BF00224237

[10] Netra, N. and Prasad, S. (2007) Identification of rice hybrids and their parental lines based on seed, seedling characters, chemical tests and gel electrophoresis of total soluble seed proteins. Seed Science and Technology, 35, 176-186.

[11] Talebi, R., Fayaz, F., Mardi, M., Pirsyedi, S.M. and Naji, A.M. (2008) Genetic relationships among chickpea ( $\mathrm{Ci}$ cer arietinum) elite line based on RAPD and agronomic markers. International Journal of Agriculture and Biology, 10, 301-305.

[12] Sun, G.L., Salomon, B. and Bothmer, R.V. (1998) Characterization and analysis of microsatellite loci in Elymus caninus (Triticea: poaceae). TAG Theoretical and Applied Genetics, 96, 676-682. doi:10.1007/s001220050788

[13] Laemmli, U.K. (1970) Cleavage of structural proteins during the assembly of the head of bacteriophage T4. Nature, 227, 680-685.

[14] Kang, H.W., Cho, Y.G., Yoon, U.H. and Eun, M.Y. (1998) A rapid DNA extraction method for RFLP and PCR analysis from a single dry seed. Plant Molecular Biology Reporter, 16, 1-9. doi:10.1023/A:1007418606098

[15] Subudhi, P.K., Baisakh, N., Harrison, S.A., Materne, M.D. and Utomo, H. (2007) Plant genetic diversity: Essential for a dynamic Louisiana coast. Louisiana Agriculture, 50, 21.

[16] Dangi, R.S., Lagu, M.D., Choudhary, L.B., Ranjekar, P.K. and Gupta, V.S. (2004) Assessment of genetic diversity in Trigonella foenum graceum and Trigonella caerulea using ISSR and RAPD markers. Plant Biology, 4, 13.
[17] Acharya, S.N., Basu, S.K., Datta, S. and Prasad, R. (2010) Genotype X environment interactions and its impact on use of medicinal plants. Open Nutraceuticals Journal, 3, 47-54.

[18] Tai, G.C.C. (1971) Genotypic stability analysis and its application to potato regional trials. Crop Science, 11, 184-190. doi:10.2135/cropsci1971.0011183X001100020006x

[19] Iruela, M., Rubio, J., Cubero, J.I., Gil, J. and Milan, T. (2002) Phylogenetic analysis in the genus Cicer and cultivated chickpea using RAPD and ISSR markers. TAG Theoretical and Applied Genetics, 104, 643-651. doi:10.1007/s001220100751

[20] Varshney, R.K., Coyne, C.J., Swamy, P. and Hoisington, H. (2007) Molecular identification of genetically distinct accessions in the USDA chickpea core collection. Pisum Genetics, 39, 32-33.

[21] Joshi, N., Rawat, A., Subramanian, R.B. and Rao, K.S. (2010) A method for small scale DNA isolation from chickpea (Cicer arietinum L.) suitable for molecular marker analysis. Indian Journal of Science and Technology, 3, 12.

[22] Upadhyaya, H.D., Kumar, S., Gowda, C.L.L. and Singh, S. (2006) Two major genes for seed size in chickpea ( $C i$ cer arietinum L.). Euphytica, 147, 311-315. doi:10.1007/s10681-005-9013-3

[23] Hossain, S., et al. (2010) Inheritance of seed size in chickpea (Cicer arietinum L.) and identification of QTL based on 100-seed weight and seed size index. Australian Journal of Crop Science, 4.

[24] Nisar, M., Ghafoor, A., Ahmad, H., Khan, M.R., Qureshi, A.S., Ali, H. and Aslam, M. (2008) Evaluation of genetic diversity of pea germplasm through phenotypic trait analysis. Pakistan Journal of Botany, 40, 2081-2086.

[25] Nisar, M., Ghafoor, A., Khan, M.R. and Asmatullah (2009) First proteomic assay of Pakistan Pisum sativum germplasm relation to geographic pattern. Russian Journal of Genetics, 45, 807-812. doi:10.1134/S1022795409070072 